Article

\title{
Identification and Functional Prediction of Drought-Responsive Long Non-Coding RNA in Tomato
}

\author{
Seung Hee Eom ${ }^{1,+}$, Hee Ju Lee ${ }^{2,+}$, Jin Hyoung Lee ${ }^{2}$, Seung Hwan $\mathrm{Wi}^{2}$, Sung Kyeom Kim ${ }^{3}$ and \\ Tae Kyung Hyun ${ }^{1, *}$ \\ 1 Department of Industrial Plant Science and Technology, College of Agricultural, Life and Environmental \\ Sciences, Chungbuk National University, Cheongju 28644, Korea; eom0214@naver.com \\ 2 Vegetable Research Division, National Institute of Horticultural \& Herbal Science, Wanju 55365, Korea; \\ perpetuaa@korea.kr (H.J.L.); leejh0820@korea.kr (J.H.L.); kgad@rda.go.kr (S.H.W.) \\ 3 Department of Horticultural Science, College of Agriculture \& Life Science, Kyungpook National University, \\ Daegu 41566, Korea; skkim76@knu.ac.kr \\ * Correspondence: taekyung7708@chungbuk.ac.kr; Tel.: +82-43-261-2520; Fax: +82-43-271-0413 \\ + These authors contributed equally to this work.
}

Received: 24 September 2019; Accepted: 3 October 2019; Published: 11 October 2019

\begin{abstract}
In higher plants, several lines of evidence suggest that long non-coding RNAs (lncRNAs) may play important roles in the regulation of various biological processes by regulating gene expression. In this study, we identified a total of 521 lncRNAs, classified as intergenic, intronic, sense, and natural antisense lncRNAs, from RNA-seq data of drought-exposed tomato leaves. A further 244 drought-responsive tomato lncRNAs were predicted to be putative targets of 92 tomato miRNAs. Expression pattern and preliminary functional analysis of potential mRNA targets suggested that drought-responsive tomato lncRNAs play important roles in a variety of biological processes via lncRNA-mRNA co-expression. Taken together, these data present a comprehensive view of drought-responsive tomato lncRNAs that serve as a starting point for understanding the role of long intergenic non-coding RNAs in the regulatory mechanisms underlying drought responses in crops.
\end{abstract}

Keywords: long non-coding RNAs; drought; tomato; miRNA

\section{Introduction}

Because the world population is increasing, the global food demand is expected to approximately double by the year 2050 [1]. Meeting global food needs will require a substantial understanding of the climatic factors influencing agricultural production. Important in this regard is understanding how climate extremes caused by global warming impact crop yields. Drought, a recurring phenomenon with major impacts on natural systems, is one of the major widespread climatic extremes that negatively affect agricultural production [2,3]. Droughts led to global cereal (maize, rice, and wheat) production deficits of $10.1 \%$ on average during the past four decades [4]. Under drought conditions, crops display various physiological and biochemical responses, including stomatal movement (the opening or closing of stomata), morphological changes (repression of cell growth and development), and alteration in biosynthetic pathways, antioxidant pathways, and respiration pathways; all of these aid survival in this unfavorable climate [5]. Understanding drought-induced molecular and physiological mechanisms is necessary for successful yield protection in the context of drought.

Coding and non-coding genomic elements, including messenger RNA (mRNA) and long non-coding RNA (lncRNA), are the main subgroups of RNAs participating in transcription regulation. Generally, lncRNAs are defined as RNA transcripts characterized by a minimum length of 200 
bp and lack of coding potential [6]. In plants, the majority of lncRNAs are transcribed by RNA polymerase II similar to mRNAs, although some IncRNAs are transcribed by RNA polymerase III or the plant-specific, DNA-dependent, RNA polymerases RNA polymerase IV and V [7]. Initially, IncRNAs were thought to represent transcriptional noise with low levels of evolutionary conservation [8]; nevertheless, a growing body of evidence suggests that lncRNAs play important roles in the regulation of various biological processes, including plant growth and development, epigenetic responses, and the responses to various stresses [6,9,10]. In Arabidopsis, more than 6500 lncRNAs were identified from a number of transcriptomic datasets, with either organ-specific or stress-induced expression profiles $[9,11]$. Extensive genome-wide identification of lncRNAs has been performed in some plants, including Populus tomentosa [12], Fragaria vesca [13], Cicer arietinum [14], Ginkgo biloba [15], and Zea mays [16]. Several reports also show that biotic or abiotic stress alters lncRNA expression in plants. For example, 664 and 98 drought-responsive lncRNAs were identified in maize [17] and rice [18], respectively. The expression of 1832 Arabidopsis long intergenic non-coding RNAs (lincRNAs), which are IncRNAs transcribed from intergenic regions of the genome, were significantly altered after drought, cold, salt and/or abscisic acid (ABA) treatment [9]. Among these, drought-induced lncRNA mediate plant tolerance to drought and salt stress by modulating the expression of genes involved in ABA signaling, water transport, and other stress-relief processes [19]. Overexpression of Arabidopsis long non-protein-coding RNA 536 resulted in visible differences when compared to wild-type plants under salt stress conditions [20]. Taken together, these data suggest that the identification of stress-responsive lncRNA provides an opportunity to increase our knowledge of the contribution of lncRNAs to the stress response and to explore lncRNAs as possible targets for improving plant tolerance to stress.

In this study, in order to investigate the regulation of tomato lncRNAs in response to drought stress, we analyzed transcriptome data obtained from drought-treated tomato leaf samples. Combined with bioinformatics approaches, we further analyzed the potential function of these lncRNAs and the relationship between tomato mRNAs, IncRNAs, and miRNAs. Taken together, our results will improve our understanding of lncRNA-mediated gene regulation in drought response.

\section{Materials and Methods}

\subsection{Plant Material and Drought Treatment}

Tomato (Solanum lycopersicum cv. Amoroso) was grown under controlled conditions $\left(25^{\circ} \mathrm{C}\right.$, $70 \%$ relative humidity, and light intensity of $1000 \mu \mathrm{mol} \mathrm{m}^{-2} \mathrm{~s}^{-1}$ for $12 \mathrm{~h} /$ day). For drought stress treatment, 4-week-old plants were subjected to water deprivation for $4 \mathrm{~d}$, and non-treated plants were well-watered throughout the experiment. Leaves from drought-treated and control tomato plants were collected for total RNA isolation. The experiment was conducted with 3 replicates per treatment and 10 plants per replicate.

\subsection{Transcriptome Data and Transcriptome Assembly}

RNA-seq data from drought-treated tomato leaf samples were obtained from the National Agricultural Biotechnology Information Center (NABIC, http://nabic.rda.go.kr) with accession number NN-5505 [21]. Then, the quality of the raw data was controlled by using the FastQC tool and Trimmomatic v.0.33 as described by Eom et al. [5]. The clean reads were mapped to the tomato reference sequence (Tomato Genome version SL3.0 and Annotation ITAG3.10, https://solgenomics.net/ organism/Solanum_lycopersicum/genome), using the HISAT2 aligner (http://ccb.jhu.edu/software/ hisat2/index.shtml ). Then, these mapped reads were further assembled and merged using StringTie (https://ccb.jhu.edu/software/stringtie).

\subsection{Long Non-Coding RNA Identification}

LncRNAs were identified using the following workflow: Step 1, unknown transcripts with lengths longer than 200 nucleotides (nt), and FPKM (fragments per kilobase of transcript per million fragments 
mapped) more than 0.1 were selected as IncRNA candidates; Step 2, transcripts with ORFs (open reading frames) $>300 \mathrm{bp}$ and other non-coding RNAs (e.g., rRNAs, tRNAs, snoRNAs, snRNAs) were removed using gffcompare; Step 3, the coding potential of the remaining transcripts was evaluated using the coding potential calculator (CPC, CPC score $<0$ ) software (http://cpc.cbi.pku.edu.cn/), BlastX search against all plant protein sequences in the Swiss-Prot database, and PfamScan (protein family database, $E$-value $<0.001$ ); Step 4, transcripts that passed these steps were annotated as IncRNAs; and Step 5, a long non-coding RNA Scan (lncRScan) program was used to categorize the identified lncRNAs as described by Sun et al. [22].

\subsection{Prediction and Functional Annotation of Long Non-Coding RNA Targets}

To explore whether IncRNAs function as miRNA decoys, all identified lncRNAs were analyzed for miRNA target sites using psRNATarget webserver (https://plantgrn.noble.org/psRNATarget/analysis). The interaction between tomato miRNAs and the identified lincRNAs was calculated using the following parameters: maximum expectation $=5$ and allowed maximum energy to unpair the target site $(\mathrm{UPE})=25$, as described by Hou et al. [23]. A lower UPE implies a higher possibility of establishing a contact between an miRNA and the target lncRNA. The interaction network of lincRNAs and miRNAs was drawn using Cytoscape software (Agilent Technologies Co., Santa Clara, CA, USA).

The potential target genes of drought-responsive lncRNAs were predicted using cis role analysis, as described by Wang et al. [15]. These IncRNA target genes were functionally annotated using Gene Ontology (GO) $(p<0.05)($ http://geneontology.org/).

\subsection{Quantitative Reverse Transcription-Polymerase Chain Reaction Analysis}

The expression levels of selected miRNAs, lncRNAs and target genes were analyzed using quantitative reverse transcription-polymerase chain reaction (RT-qPCR). To analyze tomato miRNA expression, total RNA was extracted from drought-treated or non-treated tomato plants using TRIzol Reagent (Invitrogen, Carlsbad, CA, USA) according to the manufacturer's instructions and treated with DNase I to remove any contaminating DNA. cDNA was synthesized using a Mir-X miRNA First-Strand Synthesis kit (Clontech Takara, Seoul, Korea) according to the manufacturer's instructions. For analyzing the expression of lncRNAs and target genes, total RNA was extracted using the FavorPrep Plant Total RNA Mini Kit and reverse-transcribed into cDNA using the ReverTra Ace ${ }^{\circledR}$ qPCR RT Master Mix with qDNA Remover (TOYOBO, Co., Ltd., Osaka, Japan), according to the manufacturer's instructions. RT-qPCR was performed using the SYBR ${ }^{\circledR}$ Green Real-Time PCR Master Mix (Toyobo, Co., Ltd., Osaka, Japan) in a CFX96TM real-time system (Bio-Rad, Hercules, CA, USA), with the following PCR conditions: $95^{\circ} \mathrm{C}$ for $10 \mathrm{~s}, 40$ cycles of $95^{\circ} \mathrm{C}$ for $5 \mathrm{~s}$, and $60^{\circ} \mathrm{C}$ for $20 \mathrm{~s}$. Sample cycle threshold (Ct) values were determined and standardized relative to the tomato ACTIN 4 gene (Solyc04g011500), and the $2^{-\Delta \Delta C t}$ method was used to calculate the relative expression of selected miRNAs, IncRNAs, and target genes. The specific primer pairs used in RT-qPCR are listed in Table S1.

\subsection{Statistical Analysis}

To determine the significance of differences between the groups, one-way analysis of variance (ANOVA) based on Duncan's multiple range tests $(p<0.05)$ was used. All experiments were repeated at least three times, and the results were presented as mean \pm standard error.

\section{Results and Discussion}

\subsection{Identification and Characterization of Drought-Responsive Tomato Long Non-Coding RNAs}

To understand the molecular mechanisms of tomato lncRNA responses to drought stress, the raw reads from RNA-seq data were analyzed. After removing low-quality reads, approximately 55 million paired-end clean reads were obtained from RNA-seq data generated from drought-treated tomato leaf samples (NN-5505) and were mapped and assembled as described in the methods section. To obtain 
confident lncRNA transcripts, we performed severalrounds of core filtering of transcripts with high sequence similarity to known proteins, protein-coding potentials, or open-reading frames. Using this comprehensive filtering pipeline, we finally identified 521 lncRNA expressed in drought-treated tomato leaves (Table S2). To characterize the basic genomic features of tomato lncRNAs, we analyzed their length and distribution on the chromosomes of tomato. The length of lncRNAs ranged from 201 to $6701 \mathrm{nt}$, with an average of $916 \mathrm{nt}$, and there were 362 lncRNAs with lengths varying from 200 to $1000 \mathrm{nt}$ (Figure 1a). We also found that the drought-responsive lncRNAs were transcribed from all 12 chromosomes. Chromosome 1 had the highest number of lncRNA loci (57), followed by chromosome 2 (47) and chromosome 7 (47), whereas chromosome 11 had the lowest number of lncRNA loci (32) (Figure 1b).

(a)

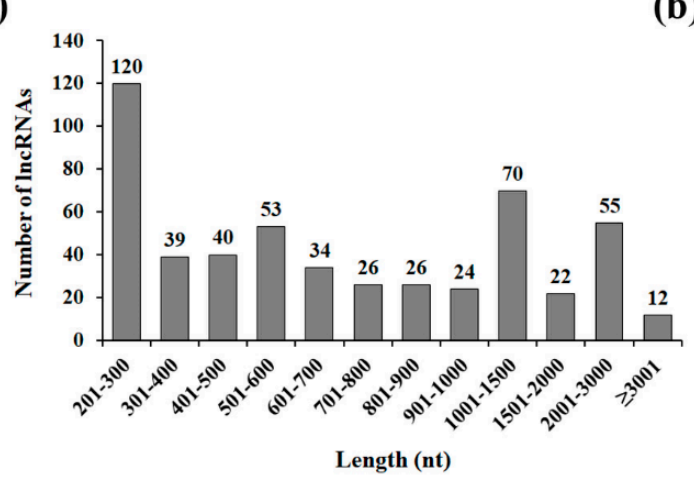

(c)

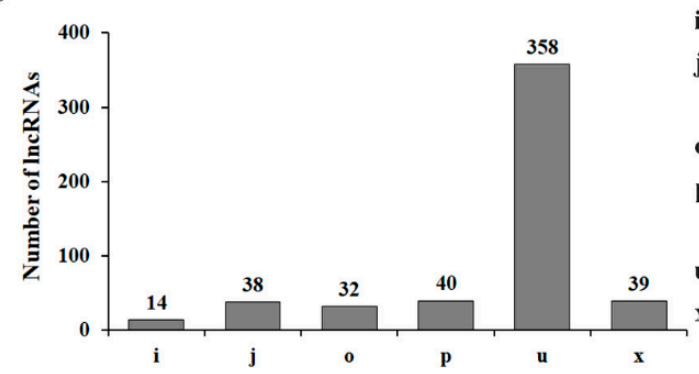

(b)

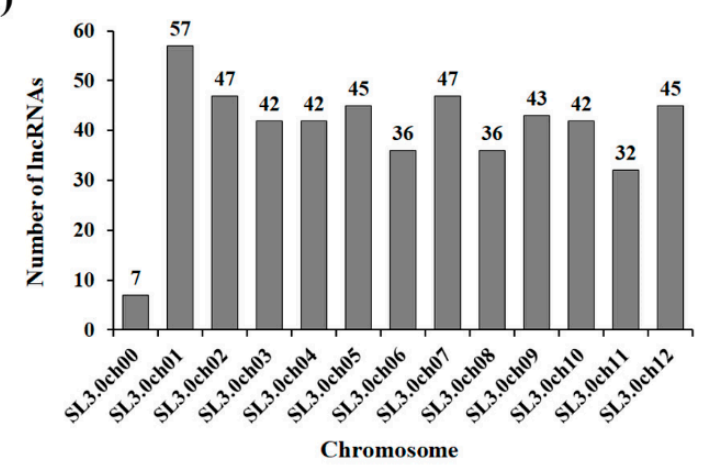

i: A transfrag falling entirely within a reference intron.

j: Potentially novel isoform (fragment): at least one splice junction is shared with a reference transcript.

o: Generic exonic overlap with a reference transcript.

p: Possible polymerase run-on fragment (within $2 \mathrm{Kbases}$ of a reference transcript).

u: Unknown, intergenic transcript.

$\mathbf{x}$ : Exonic overlap with reference on the opposite strand.

Figure 1. Characteristics of drought-responsive tomato long non-coding RNAs (lncRNAs). (a) Length distribution of lncRNAs. (b) Chromosome-wise distribution of long intergenic non-coding RNAs (lincRNAs). (c) Classification of lincRNAs.

On the basis of the relationship with protein-coding genes and the genomic location, most plant lncRNAs have been classified as intergenic, intronic, sense, and natural antisense lncRNAs [24]. To characterize drought-responsive tomato lncRNAs, the identified lncRNAs were further classified into six categories by comparison with the known gene annotations. As shown in Figure 1c, 358 lncRNAs and 40 lncRNAs were assigned the ' $u$ ' classcode, defining the "unknown intergenic transcript" and the ' $\mathrm{p}$ ' classcode, defining the "possible polymerase run-on fragment," respectively. The identified lncRNAs from ' $u$ ' and ' $p$ ' classes were considered to be lincRNAs, as suggested by Wang et al. [25]. A total of 39 lncRNAs with the ' $x$ ' classcode had exonic overlap with references on the opposite strand, such as the natural antisense lncRNAs. A total of $14 \operatorname{lncRNAs}$ with the ' $i$ ' classcode fell entirely within the reference intron, including the intronic lncRNAs. A total of 70 candidates in classes ' $j$ ' (potentially novel isoform) and ' $\mathrm{o}$ ' (unknown, generic overlap with reference) were considered to be sense IncRNAs, suggesting that lincRNAs accounted for the largest proportion of drought-responsive tomato lncRNAs. Because thousands of lincRNAs have been identified in human and plant genomes $[9,17,26]$, a few studies have revealed the function of lincRNAs, including transcriptional regulation by recruiting proteins for chromosome modification to specific loci, inhibition of the physical interaction between miRNAs and their target mRNAs, and controlling alternative splicing [27]. Although the physiological 
function of drought-responsive lincRNAs remains unclear, some drought-responsive Populus lincRNAs are thought to serve as putative targets of Populus miRNAs [28]. This suggests that miRNA-lncRNAs (such as lincRNAs) interactions might play key roles in drought stress tolerance.

\subsection{Drought-Responsive Tomato Long Non-Coding RNA Transcripts as Potential Targets of Tomato miRNAs}

miRNAs and lncRNAs are two important types of non-coding RNA, and their interactions play important roles in various biological processes, including plant growth, development, and reproduction $[29,30]$. LncRNAs that interact with miRNA function as endogenous target mimics $[27,31]$. To investigate the interaction between our identified lncRNAs and tomato miRNAs, our identified lncRNAs as targets of tomato miRNAs were predicted using psRNATarget server [32]. An alignment of tomato miRNAs with 521 lncRNA suggested that a total of 244 drought-responsive tomato lncRNAs were putative targets of 92 tomato miRNAs (Table S3). As shown in Figure 2, multiple interaction patterns, including one lncRNA with many miRNAs, many lncRNAs with one miRNA, and many lncRNAs with many miRNAs were identified. This resulted in a total of 538 lncRNA-miRNA interactions (Table S3). The majority of miRNAs involved in interactions with lncRNAs were of the sly-miR156, sly-miR390, sly-miR482, sly-miR5302, and sly-miR9476 families. miR156 is one of the most conserved and highly expressed miRNAs in plants. In higher plants, overexpression of miR156 resulted in dramatic morphologic changes, including delayed flowering, increased root development, and enhanced biomass production, suggesting that miR156 has important regulatory functions in plant growth and development [33-36]. In addition, miR156 regulates tolerance to environmental stresses such as salt and drought stresses via downregulation of the SPL (squamosa promoter-binding protein-like) transcription factor family genes. These genes are master regulators of various biological processes, including vegetative to reproductive phase change, secondary metabolism, and stress responses $[33,37,38]$.
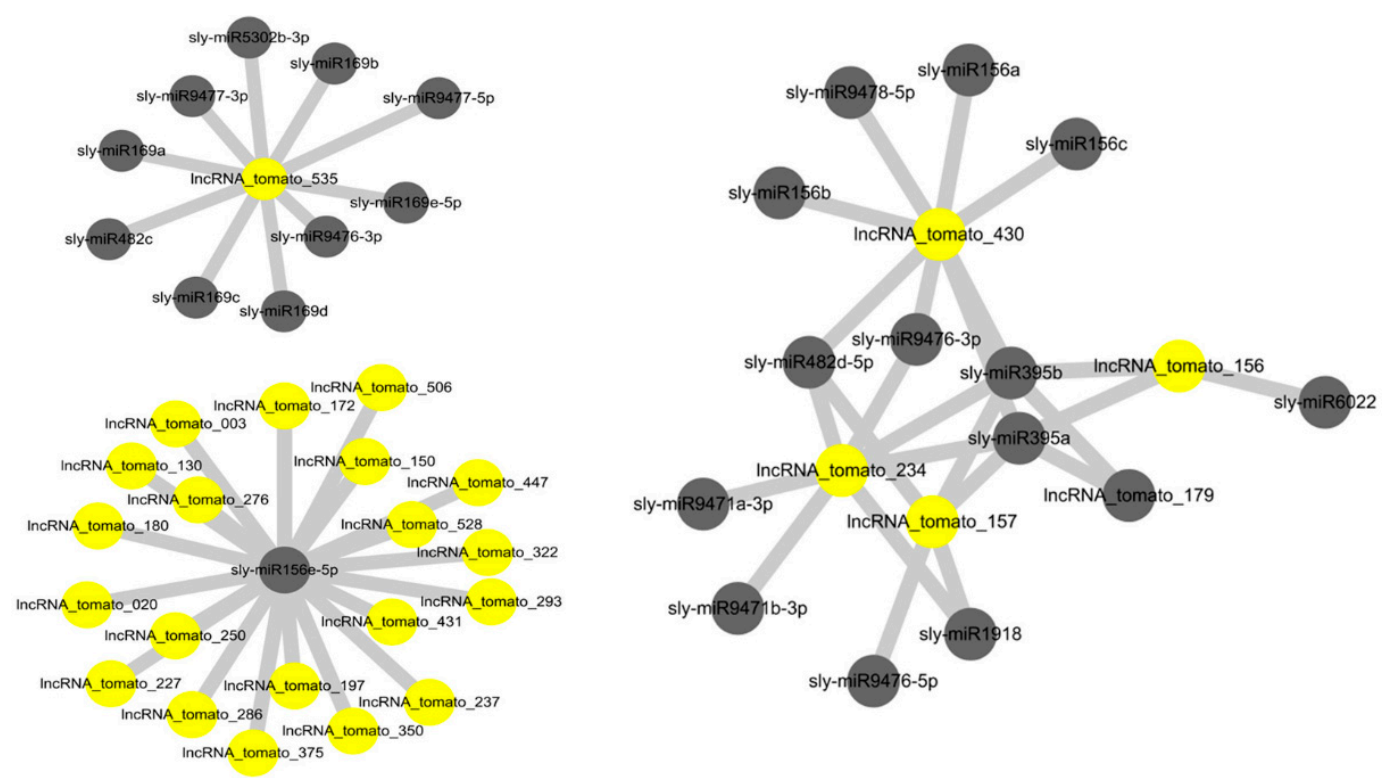

Figure 2. LncRNA-miRNA interaction network. Yellow circle nodes represent lncRNAs, and gray circle nodes represent miRNAs. Examples of interactions are shown: one lncRNA with many miRNAs, one miRNA with many lncRNAs, and many lncRNAs with many miRNAs.

It has been shown that the expression of miR169 is regulated by CBF/DREB (C-repeat-binding factor/dehydration-responsive element binding factor) transcription factors [39,40]. In addition, overexpression of miR396 enhanced drought tolerance [41], suggesting the role of miR169 and miR396 in drought response. To investigate the relationship between miRNAs (miR169 and miR396) and their target lncRNAs, four IncRNA-miRNA pairs were selected and subjected to qRT-PCR 
to predict and classify possible functions of drought-responsive tomato lncRNAs. As shown in Figure 4, metabolic process and cellular process were prominently represented under the biological process category. Furthermore, cell and cell part represented the majority of terms in the cellular component category, and the vast majority was related to binding and catalytic activity in the molecular function category. Furthermore, we also found GO terms related to stress tolerance, including response to stimulus (nine genes), signaling (three genes), and transporter activity (six genes), suggesting that some lncRNAs might contribute to drought stress tolerance via control of target gene expression.

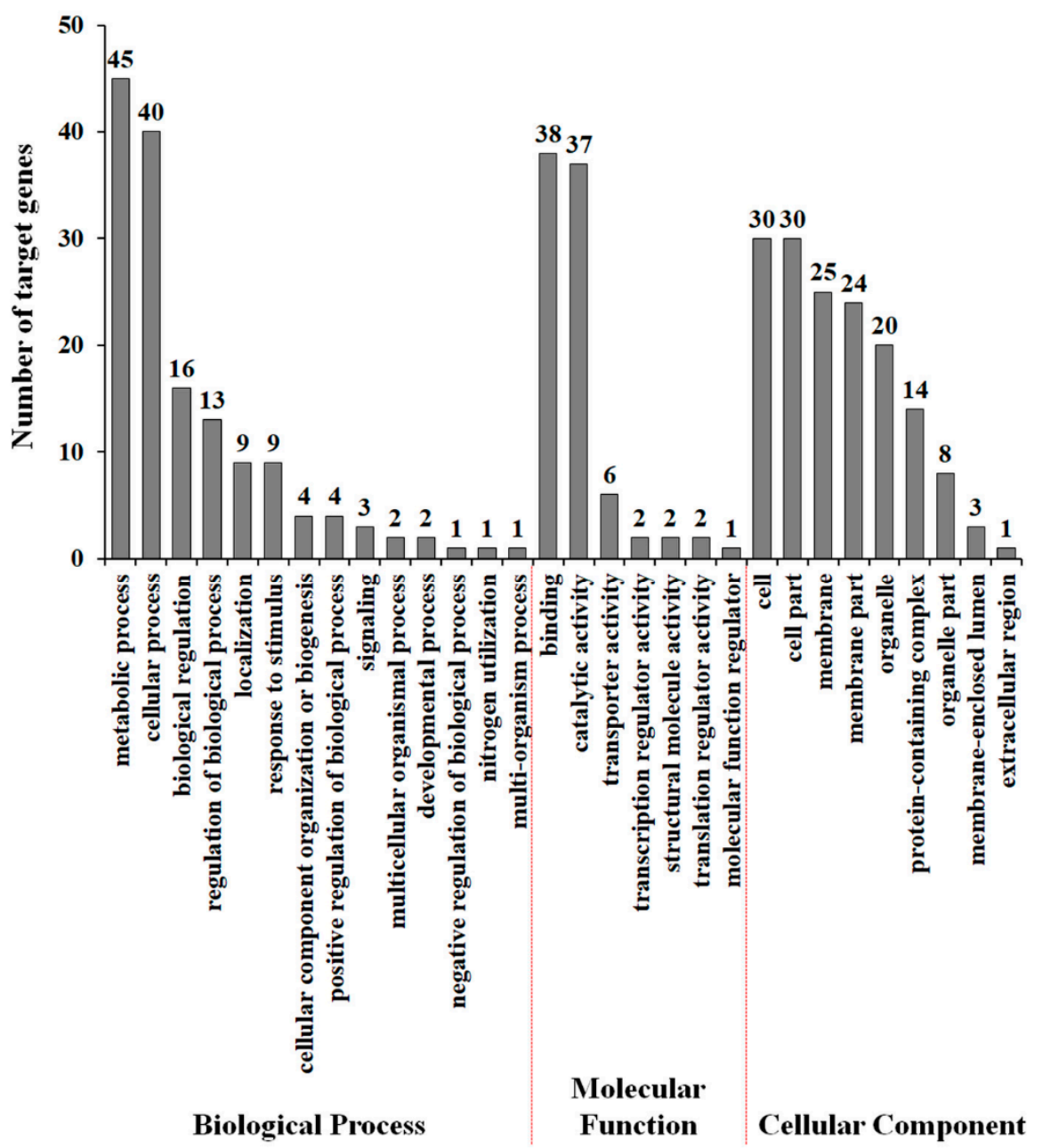

Figure 4. Gene ontology classification of lncRNA target genes. The results are summarized in three main categories: biological process, molecular function, and cellular component.

To determine the relationship between expression of drought-responsive tomato lncRNAs and their potential target genes, three lncRNA and target gene pairs were selected, and we analyzed expression patterns in response to drought stress. Under drought conditions, lncRNA_tomato_467 and its potential target gene associated with $\mathrm{K}^{+}$channel, Solyc11g011500.2 [49], were upregulated, whereas other lncRNAs and their target genes were downregulated (Figure 5). This suggests that all tested pairs of lncRNAs and their putative target genes share similar transcription patterns and might be transcriptionally co-regulated. In guard cells, $\mathrm{K}^{+}$channel activity mediated by either ABA-induced $\mathrm{Ca}^{+}$-dependent or -independent pathways was required for stomatal movements [50], indicating that drought-induced lncRNA_tomato_467 and Solyc11g011500.2 might play roles in stomatal movement via controlling $\mathrm{K}^{+}$levels. It is known that ABA-mediated physiological processes, including closure of the stomata and acceleration of leaf senescence, are counteracted by cytokinins [51]. Trans-zeatin (tZ), an active cytokinin, is catalyzed by zeatin O-glucosyltransferase, 
and this process is required for protection of zeatin from cyctokinin oxidases/dehydrogenases [52]. In zeatin-O-glucosyltransferase-overexpressing plants, a delay in the accumulation of drought-induced ABA was observed, resulting in the delayed decrease of stomatal aperture in response to water deficit [53]. This suggests that the downregulation of zeatin o-glucosyltransferase, Solyc11g066670.1 [54], should be essential for ABA-induced stomatal closure in response to drought stress. In addition, drought-exposed plants exhibited a specific decrease in abundance of the ATP synthase complex, including the epsilon subunit of the chloroplast ATP-synthase-like Solyc01g017220.1 [55] due to water-deficit-induced biochemical limitation in photosynthesis, indicating that lncRNA_tomato_025 should be an important resource for improving chloroplast energy balance in response to drought stress. Taken together, these findings suggest that some drought-responsive lncRNAs act as transcriptional regulators of drought responses in tomato.

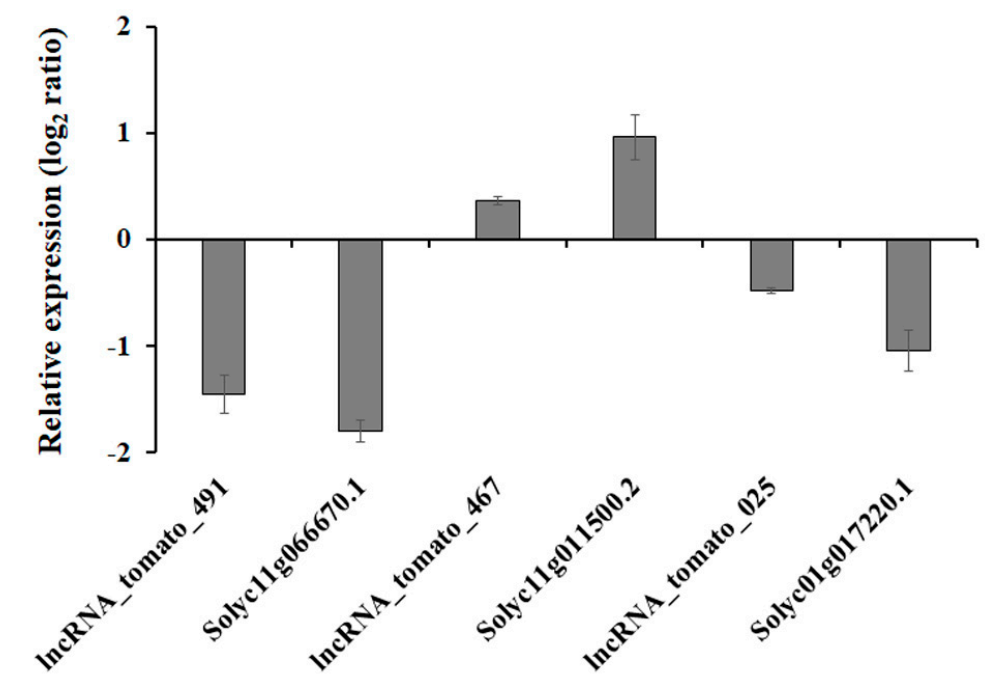

Figure 5. Transcriptional changes of selected lncRNA-mRNA pairs during the response to drought stress. Transcript levels of the selected lncRNA-mRNA pairs were normalized to those of tomato actin and were expressed relative to the values in the non-treated sample. The level of expression is represented as the $\log 2$ ratio. Data are means \pm SE.

\section{Conclusions}

We identified and characterized 521 putative lncRNAs expressed in drought-treated tomato leaves. Several drought-responsive lncRNAs acted as putative targets of tomato miRNAs. The prediction of lncRNA-mRNA interaction and GO enrichment analysis suggested that drought-responsive lncRNAs act as transcriptional regulators of genes involved in stress tolerance, including response to stimulus, signaling, and transporter activity. These findings provide valuable information for further characterization of lncRNA-mediated regulatory mechanisms underlying drought stress. Understanding the interactions of IncRNAs with other molecular elements is an interesting area that needs to be further developed to improve our knowledge of drought-induced molecular and physiological mechanisms.

Supplementary Materials: The following are available online at http://www.mdpi.com/2073-4395/9/10/629/s1, Table S1: The primers of miRNAs, IncRNAs and target genes used for qRT-PCR analysis, Table S2: Details of drought-responsive lncRNAs, Table S3: List of miRNAs targeting the drought-responsive tomato lncRNAs.

Author Contributions: Conceptualization, S.H.E., H.J.L., and T.K.H.; methodology, S.H.E., H.J.L., S.K.K., and T.K.H.; formal analysis, S.H.E., H.J.L., and S.H.W.; investigation, S.H.E., H.J.L., J.H.L.; data curation, S.H.E., H.J.L., J.H.L.; writing-original draft preparation, S.H.E., H.J.L., and T.K.H.; writing-review and editing, S.H.E., H.J.L., J.H.L., S.H.W., S.K.K., and T.K.H.

Funding: This work was carried out with the support of "Cooperative Research Program for Agriculture Science and Technology Development (Project No. PJ01261303)" Rural Development Administration, Republic of Korea. 
Conflicts of Interest: The authors declare no conflict of interest.

\section{References}

1. Tilman, D.; Balzer, C.; Hill, J.; Befort, B.L. Global food demand and the sustainable intensification of agriculture. Proc. Natl. Acad. Sci. USA 2011, 108, 20260-20264. [CrossRef]

2. Reichstein, M.; Bahn, M.; Ciais, P.; Frank, D.; Mahecha, M.D.; Seneviratne, S.I.; Zscheischler, J.; Beer, C.; Buchmann, N.; Frank, D.C.; et al. Climate extremes and the carbon cycle. Nature 2013, 500, 287-295. [CrossRef] [PubMed]

3. Zipper, S.C.; Qiu, J.; Kucharik, C.J. Drought effects on US maize and soybean production: Spatiotemporal patterns and historical changes. Environ. Res. Lett. 2016, 11, 094021. [CrossRef]

4. Lesk, C.; Rowhani, P.; Ramankutty, N. Influence of extreme weather disasters on global crop production. Nature 2016, 529, 84-87. [CrossRef]

5. Eom, S.H.; Baek, S.A.; Kim, J.K.; Hyun, T.K. Transcriptome analysis in Chinese cabbage (Brassica rapa ssp. pekinensis) provides the role of glucosinolate metabolism in response to drought stress. Molecules 2018, 23, E1186. [CrossRef] [PubMed]

6. Chekanova, J.A. Long non-coding RNAs and their functions in plants. Curr. Opin. Plant Biol. 2015, 27, 207-216. [CrossRef] [PubMed]

7. Rowley, M.J.; Böhmdorfer, G.; Wierzbicki, A.T. Analysis of long non-coding RNAs produced by a specialized RNA polymerase in Arabidopsis thaliana. Methods 2013, 63, 160-169. [CrossRef] [PubMed]

8. Rinn, J.L.; Chang, H.Y. Genome regulation by long noncoding RNAs. Annu. Rev. Biochem. 2012, 81, 145-166. [CrossRef]

9. Liu, J.; Jung, C.; Xu, J.; Wang, H.; Deng, S.; Bernad, L.; Arenas-Huertero, C.; Chua, N.H. Genome-wide analysis uncovers regulation of long intergenic noncoding RNAs in Arabidopsis. Plant Cell 2012, 24, 4333-4345. [CrossRef] [PubMed]

10. Sun, X.; Zheng, H.; Sui, N. Regulation mechanism of long non-coding RNA in plant response to stress. Biochem. Biophys. Res. Commun. 2018, 503, 402-407. [CrossRef] [PubMed]

11. Zhao, X.; Li, J.; Lian, B.; Gu, H.; Li, Y.; Qi, Y. Global identification of Arabidopsis lncRNAs reveals the regulation of MAF4 by a natural antisense RNA. Nat. Commun. 2018, 9, 5056. [CrossRef] [PubMed]

12. Chen, J.H.; Quan, M.Y.; Zhang, D.Q. Genome-wide identification of novel long non-coding RNAs in Populus tomentosa tension wood, opposite wood and normal wood xylem by RNA-seq. Planta 2014, 241, 125-143. [CrossRef] [PubMed]

13. Kang, C.Y.; Liu, Z.C. Global identification and analysis of long non-coding RNAs in diploid strawberry Fragaria vesca, during flower and fruit development. BMC Genom. 2015, 16, 815. [CrossRef] [PubMed]

14. Khemka, N.; Singh, V.K.; Garg, R.; Jain, M. Genome-wide analysis of long intergenic non-coding RNAs in chickpea and their potential role in flower development. Sci. Rep. 2016, 6, 33297. [CrossRef] [PubMed]

15. Wang, L.; Xia, X.; Jiang, H.; Lu, Z.; Cui, J.; Cao, F.; Jin, B. Genome-wide identification and characterization of novel lncRNAs in Ginkgo biloba. Trees 2018, 32, 1429-1442. [CrossRef]

16. Li, L.; Eichten, S.R.; Shimizu, R.; Petsch, K.; Yeh, C.T.; Wu, W.; Chettoor, A.M.; Givan, S.A.; Cole, R.A.; Fowler, J.E.; et al. Genome-wide discovery and characterization of maize long non-coding RNAs. Genome Biol. 2014, 15, R40. [CrossRef] [PubMed]

17. Zhang, Y.C.; Liao, J.Y.; Li, Z.Y.; Yu, Y.; Zhang, J.P.; Li, Q.F.; Qu, L.H.; Shu, W.S.; Chen, Y.Q. Genome-wide screening and functional analysis identify a large number of long noncoding RNAs involved in the sexual reproduction of rice. Genome Biol. 2014, 15, 512. [CrossRef] [PubMed]

18. Chung, P.J.; Jung, H.; Jeong, D.H.; Ha, S.H.; Choi, Y.D.; Kim, J.K. Transcriptome profiling of drought responsive noncoding RNAs and their target genes in rice. BMC Genom. 2016, 17, 563. [CrossRef]

19. Qin, T.; Zhao, H.; Cui, P.; Albesher, N.; Xiong, L. A nucleus-localized long non-coding RNA enhances drought and salt stress tolerance. Plant Physiol. 2017, 175, 1321-1336. [CrossRef]

20. Ben Amor, B.; Wirth, S.; Merchan, F.; Laporte, P.; d'Aubenton-Carafa, Y.; Hirsch, J.; Maizel, A.; Mallory, A.; Lucas, A.; Deragon, J.M.; et al. Novel long non-protein coding RNAs involved in Arabidopsis differentiation and stress responses. Genome Res. 2009, 19, 57-69. [CrossRef] 
21. Lee, H.J.; Eom, S.H.; Lee, J.H.; Wi, S.H.; Kim, S.K.; Hyun, T.H. Genome-wide analysis of alternative splicing events during response to drought stress in tomato (Solanum lycopersicum L.). J. Hortic. Sci. Biotechnol. 2019. [CrossRef]

22. Sun, L.; Zhang, Z.; Bailey, T.L.; Perkins, A.C.; Tallack, M.R.; Xu, Z.; Liu, H. Prediction of novel long non-coding RNAs based on RNA-Seq data of mouse Klf1 knockout study. BMC Bioinform. 2012, 13, 331. [CrossRef]

23. Hou, X.; Du, Y.; Liu, X.; Zhang, H.; Liu, Y.; Yan, N.; Zhang, Z. Genome-wide analysis of long non-coding RNAs in potato and their potential role in tuber sprouting process. Int. J. Mol. Sci. 2017, 19, E101. [PubMed]

24. Yu, T.; Zhu, H. Long non-coding RNAs: Rising regulators of plant reproductive development. Agronomy 2019, 9, 53. [CrossRef]

25. Wang, Y.; Ye, W.; Wang, Y. Genome-wide identification of long non-coding RNAs suggests a potential association with effector gene transcription in Phytophthora sojae. Mol. Plant Pathol. 2018, 19, 2177-2186. [CrossRef] [PubMed]

26. Ulitsky, I.; Bartel, D.P. lincRNAs: Genomics, evolution, and mechanisms. Cell 2013, 154, 26-46. [CrossRef] [PubMed]

27. Yamada, M. Functions of long intergenic non-coding (linc) RNAs in plants. J. Plant Res. 2017, 130, 67-73. [CrossRef] [PubMed]

28. Shuai, P.; Liang, D.; Tang, S.; Zhang, Z.; Ye, C.Y.; Su, Y.; Xia, X.; Yin, W. Genome-wide identification and functional prediction of novel and drought-responsive lincRNAs in Populus trichocarpa. J. Exp. Bot. 2014, 65, 4975-4983. [CrossRef] [PubMed]

29. Kim, E.D.; Sung, S. Long noncoding RNA: Unveiling hidden layer of gene regulatory networks. Trends Plant Sci. 2012, 17, 16-21. [CrossRef]

30. Liu, X.; Hao, L.; Li, D.; Zhu, L.; Hu, S. Long non-coding RNAs and their biological roles in plants. Genom. Proteom. Bioinform. 2015, 13, 137-147. [CrossRef] [PubMed]

31. Wu, H.J.; Wang, Z.M.; Wang, M.; Wang, X.J. Widespread long noncoding RNAs as endogenous target mimics for microRNAs in plants. Plant Physiol. 2013, 161, 1875-1884. [CrossRef] [PubMed]

32. Dai, X.; Zhuang, Z.; Zhao, P.X. psRNATarget: A plant small RNA target analysis server (2017 release). Nucleic Acids Res. 2018, 46, W49-W54. [CrossRef] [PubMed]

33. Xie, K.; Shen, J.; Hou, X.; Yao, J.; Li, X.; Xiao, J.; Xiong, L. Gradual increase of miR156 regulates temporal expression changes of numerous genes during leaf development in rice. Plant Physiol. 2012, 158, 1382-1394. [CrossRef] [PubMed]

34. Fu, C.; Sunkar, R.; Zhou, C.; Shen, H.; Zhang, J.Y.; Matts, J.; Wolf, J.; Mann, D.G.; Stewart, C.N., Jr.; Tang, Y.; et al. Overexpression of miR156 in switchgrass (Panicum virgatum L.) results in various morphological alterations and leads to improved biomass production. Plant Biotechnol. J. 2012, 10, 443-452. [CrossRef] [PubMed]

35. Cui, L.G.; Shan, J.X.; Shi, M.; Gao, J.P.; Lin, H.X. The miR156-SPL9-DFR pathway coordinates the relationship between development and abiotic stress tolerance in plants. Plant J. 2014, 80, 1108-1117. [CrossRef] [PubMed]

36. Wang, Y.; Wang, Z.; Amyot, L.; Tian, L.; Xu, Z.; Gruber, M.Y.; Hannoufa, A. Ectopic expression of miR156 represses nodulation and causes morphological and developmental changes in Lotus japonicus. Mol. Genet. Genom. 2015, 290, 471-484. [CrossRef] [PubMed]

37. Arshad, M.; Feyissa, B.A.; Amyot, L.; Aung, B.; Hannoufa, A. MicroRNA156 improves drought stress tolerance in alfalfa (Medicago sativa) by silencing SPL13. Plant Sci. 2017, 258, 122-136. [CrossRef] [PubMed]

38. Stief, A.; Altmann, S.; Hoffmann, K.; Pant, B.D.; Scheible, W.R.; Bäurle, I. Arabidopsis miR156 regulates tolerance to recurring environmental stress through spl transcription factors. Plant Cell 2014, 26, 1792-1807. [CrossRef] [PubMed]

39. Macovei, A.; Gill, S.S.; Tuteja, N. MicroRNAs as promising tools for improving stress tolerance in rice. Plant Signal. Behav. 2012, 7, 1296-1301. [CrossRef] [PubMed]

40. Zhao, B.; Liang, R.; Ge, L.; Li, W.; Xiao, H.; Lin, H.; Ruan, K.; Jin, Y. Identification of drought-induced microRNAs in rice. Biochem. Biophys. Res. Commun. 2007, 354, 585-590. [CrossRef] [PubMed]

41. Yang, F.X.; Yu, D.Q. Overexpression of Arabidopsis miR396 enhances drought tolerance in transgenic tobacco plants. Acta Bot. Yunnan. 2010, 31, 421-426. [CrossRef]

42. Huang, Z.A.; Huang, Y.A.; You, Z.H.; Zhu, Z.; Sun, Y. Novel link prediction for large-scale miRNA-lncRNA interaction network in a bipartite graph. BMC Med. Genom. 2018, 11, 113. [CrossRef] [PubMed] 
43. Deng, F.; Zhang, X.; Wang, W.; Yuan, R.; Shen, F. Identification of Gossypium hirsutum long non-coding RNAs (lncRNAs) under salt stress. BMC Plant Biol. 2018, 18, 23. [CrossRef] [PubMed]

44. Zhang, J.; Liu, L.; Li, J.; Le, T.D. LncmiRSRN: Identification and analysis of long non-coding RNA related miRNA sponge regulatory network in human cancer. Bioinformatics 2018, 34, 4232-4240. [CrossRef] [PubMed]

45. Schor, I.E.; Bussotti, G.; Maleš, M.; Forneris, M.; Viales, R.R.; Enright, A.J.; Furlong, E.E.M. Non-coding RNA expression, function, and variation during Drosophila embryogenesis. Curr. Biol. 2018, 28, 3547-3561. [CrossRef] [PubMed]

46. Scruggs, B.S.; Gilchrist, D.A.; Nechaev, S.; Muse, G.W.; Burkholder, A.; Fargo, D.C.; Adelman, K. Bidirectional transcription arises from two distinct hubs of transcription factor binding and active chromatin. Mol. Cell 2015, 58, 1101-1112. [CrossRef] [PubMed]

47. Ørom, U.A.; Derrien, T.; Beringer, M.; Gumireddy, K.; Gardini, A.; Bussotti, G.; Lai, F.; Zytnicki, M.; Notredame, C.; Huang, Q.; et al. Long noncoding RNAs with enhancer-like function in human cells. Cell 2010, 143, 46-58. [CrossRef]

48. Camblong, J.; Iglesias, N.; Fickentscher, C.; Dieppois, G.; Stutz, F. Antisense RNA stabilization induces transcriptional gene silencing via histone deacetylation in S. cerevisiae. Cell 2007, 131, 706-717. [CrossRef]

49. Zhao, X.; Liu, Y.; Liu, X.; Jiang, J. Comparative transcriptome profiling of two tomato genotypes in response to potassium-deficiency stress. Int. J. Mol. Sci. 2018, 19, E2402. [CrossRef]

50. Shabala, S. Regulation of potassium transport in leaves: From molecular to tissue level. Ann. Bot. 2003, 92, 627-634. [CrossRef]

51. Tanaka, Y.; Sano, T.; Tamaoki, M.; Nakajima, N.; Kondo, N.; Hasezawa, S. Cytokinin and auxin inhibit abscisic acid-induced stomatal closure by enhancing ethylene production in Arabidopsis. J. Exp. Bot. 2006, 57, 2259-2266. [CrossRef] [PubMed]

52. Veach, Y.K.; Martin, R.C.; Mok, D.W.; Malbeck, J.; Vankova, R.; Mok, M.C. O-glucosylation of cis-zeatin in maize. Characterization of genes, enzymes, and endogenous cytokinins. Plant Physiol. 2003, 131, 1374-1380. [CrossRef] [PubMed]

53. Havlová, M.; Dobrev, P.I.; Motyka, V.; Storchová, H.; Libus, J.; Dobrá, J.; Malbeck, J.; Gaudinová, A.; Vanková, R. The role of cytokinins in responses to water deficit in tobacco plants over-expressing trans-zeatin O-glucosyltransferase gene under 35S or SAG12 promoters. Plant Cell Environ. 2008, 31, 341-353. [CrossRef]

54. Keshishian, E.A.; Hallmark, H.T.; Ramaraj, T.; Plačková, L.; Sundararajan, A.; Schilkey, F.; Novák, O.; Rashotte, A.M. Salt and oxidative stresses uniquely regulate tomato cytokinin levels and transcriptomic response. Plant Direct 2018, 2, e00071. [CrossRef] [PubMed]

55. Hoshiyasu, S.; Kohzuma, K.; Yoshida, K.; Fujiwara, M.; Fukao, Y.; Yokota, A.; Akashi, K. Potential involvement of N-terminal acetylation in the quantitative regulation of the $\varepsilon$ subunit of chloroplast ATP synthase under drought stress. Biosci. Biotechnol. Biochem. 2013, 77, 998-1007. [CrossRef] [PubMed] 